\title{
Facing Terminal Ileitis: Going Beyond Crohn's Disease
}

\author{
Ricardo de Alvares Goulart ${ }^{\mathrm{a}}$, Sandra Maria Barbalho ${ }^{\mathrm{b}}$, , Rodrigo Galhardi Gasparinia \\ Antonely de Cassio Alves de Carvalho ${ }^{\mathrm{c}}$
}

\begin{abstract}
Terminal ileitis (TI) is an inflammatory condition of the terminal portion of the ileum that may occur acutely with right lower quadrant pain followed or not by diarrhea, or exhibit chronic obstructive symptoms and bleeding and normally it is associated to Crohn's disease (CD) although it may be associated to other different conditions. This review intended to contribute to a better understanding of TI in order to help in the diagnosis, medical approach and patient care. This work was performed on a survey of articles collected in different databases and a retrospective search was carried out to identify relevant studies in the field. Pathological conditions such as ulcerative colitis, the intake of non-steroidal anti-inflammatory drugs, infectious diseases, eosinophilic enteritis, malignant diseases, spondyloarthropathies, vasculitides, ischemia, sarcoidosis, amyloidosis and others may be related to ileitis but it is commonly referred to $\mathrm{CD}$. To a correct therapeutic approach, it is necessary to understand the causes of this inflammation process. The performance of a clinical, laboratory, endoscopic, and histopathological evaluation of the individuals is crucial to the correct diagnosis and treatment once the inflammation of the ileum may occur due to different pathological conditions besides $\mathrm{CD}$, leading to difficulties in the diagnosis. Thus, an individual approach is necessary once the correct diagnosis is crucial for the immediate therapeutic approach and recovering of the patient.
\end{abstract}

Keywords: Terminal ileitis; Inflammatory processes; Crohn's disease; Ulcerative colitis; Behcet's disease; Infectious diseases

\section{Introduction}

Terminal ileitis (TI) is an inflammatory condition of the termi-

Manuscript accepted for publication February 24, 2016

a Department of Gastroenterology, University Hospital - UNIMAR, Higino Muzzi Filho Avenue, 1001, Marilia, SP, Brazil

${ }^{b}$ Department of Biochemistry and Pharmacology, School of Medicine, University of Marilia and Food Technology School (FATEC), Higino Muzzi Filho Avenue, 1001, Marilia, SP, Brazil

'Diagnostic Center in Gastroenterology, Arthur Sampaio Street, 140, Ibaiti, PR, Brazil

${ }^{\mathrm{d} C}$ Corresponding Author: Sandra Maria Barbalho, School of Medicine, University of Marilia, Higino Muzzi Filho Avenue, 1001, Marilia, SP, Brazil.

Email: smbarbalho@gmail.com

doi: http://dx.doi.org/10.14740/gr698w nal portion of the ileum described in medical literature since a long time ago. It may occur acutely with right lower quadrant pain followed or not by diarrhea, or exhibit chronic obstructive symptoms and bleeding [1-4].

In 1936, the Epitome of Current Medical Literature [5] described the TI or ileitis terminalis and pointed that this condition recognized by Crohn in 1932 should be described as a new disease. In that Epitome, it is possible to read that "ileitis is a non-specific inflammation of the terminal portion of the ileum which sometimes spreads to the cecum causes ulceration of the intestinal mucosa, thickening and retraction of the intestinal wall... The diagnosis is based on the exclusion of specific infective processes in the ileum such as ileo-cecal tuberculosis and actinomycosis "

In 1937, again in the Epitome of Current Medical Literature [6], it is possible to find two cases of a condition named ileitis terminalis or Enteritis regionalis described in a youth aged 17, a traumatic rupture at the ileo-cecal junction, and the ileum, cecum, and appendix, exhibiting a chronic state of inflammation. A resection was reported to this case as well as an end-to-end anastomosis of the small intestine with the ascending colon. The other case described a man aged 44 with a fistula between the ileum and the bladder. Authors related resection of the lowest part of the ileum, cecum, and ascending colon.

Crohn [7] suggested that acute TI is an acute form of the disease in the terminal ileum. Kewenter and Kock [8] postulated that the follow-up of individuals with acute $\mathrm{TI}$ is the one way to identify if the acute inflammation is or not due to the Crohn's disease (CD).

As seen above, since many years ago, author's opinions are different as to whether acute TI is a separate condition or an acute form of the classical CD.

Terminal ileum is the most common affected area in CD, although any part of the gastrointestinal tract may be reached. On the other side, it may result from other situations such as infections, and a large variety of diseases may be linked to it. In clinical practice, situations that promote ileum inflammation may mimic CD both histologically and endoscopically, leading to an incorrect diagnosis and to a wrong therapeutic approach, and occasionally an unnecessary surgical procedure may be chosen $[3,4,9]$.

The possible misdiagnosis of the TI can bring many physiological and psychological problems to the patients what should make doctors look deeply and carefully to this inflammatory condition. For this reason, this review intends to contribute to a better understanding of TI in order to help in the diagnosis, medical approach and patient care. 


\section{Literature Retrieval}

This work was performed on a survey of articles collected and the following databases: Pubmed, PMC, Medline, and Lilacs. A retrospective search was carried out to identify relevant studies in the field.

\section{Pathophysiological Aspects}

In healthy individuals, the gastrointestinal microbiota interacts with the host in a perfect balance resulting in the maintenance of homeostasis and even in healthy conditions, the gastrointestinal immune system is stimulated by millions of antigens. If this balance in lost for some reason, there is a trigger in the immune system leading to an inflammatory condition that is associated to the pathophysiological processes of several diseases. The imbalance in the gastrointestinal tract is characterized by recurrent inflammation, with relapse and remission phases, and epithelial disturbance [10-14].

When the body is exposed to a pathogenic microorganism, the innate immune system is activated and a response of macrophages, dendritic cells and granulocytes, and activation of pattern recognition receptor which may recognize pathogenassociated molecular patterns normally named as PAMPs are observed. Pattern recognition receptor is capable to respond successfully conducting to the overthrowing of the bacteria and resolution of inflammation process and tissue repair. This acute inflammatory process is important to the homeostasis $[15,16]$.

In chronic inflammatory processes, epithelial cell necrosis, tissue damage, and liberation of PAMPs which are able to activate Toll-like receptors that are related to the protection of the intracellular cytosolic compartment are observed. When antigens are recognized, there is a recruitment of kinase enzymes that initiate the activation of signaling cascades and activation of nuclear factor-kappaB $(\mathrm{NF}-\kappa \mathrm{B})$ and MAPK pathways. These receptors exhibit particular pattern of immunological responses in the gastrointestinal tract [15, 17-19].

The activation of Toll-like receptors may lead to autophagy and disability to distinguish commensal from pathogenic bacteria that triggers the overproduction of tumor necrosis factor $\alpha$ (TNF- $\alpha$ ) and interleukins (ILs) such as IL-1 $\beta$, IL-6, IL-12 and IL-23. These inflammatory mediators stimulate the activation of NF- $\kappa$ B resulting in several remarkable symptoms such as pain, bleeding, and changes on the bowel habits. Besides, the inflammatory process may reach different parts of the gastrointestinal tract, including terminal portion of the ileum $[1,13$, $18,20,21]$.

Gunther et al [22] performed an interesting study showing the role for caspase- 8 in the regulation of necroptosis of intestinal epithelial cells and TI. Authors have used a mice model with a deletion of caspase- 8 in the intestinal epithelium and showed that these animals spontaneously developed inflammatory lesions in the terminal ileum and were highly susceptible to colitis. These animals possessed a smaller number of goblet cells and lacked Paneth cells what could lead to the dysregulation in the anti-microbial immune cell functions of the intestinal epithelium. These mice presented increased cell death in the Paneth cell area of small intestinal crypts induced by TNF- $\alpha$, and related to increase in the expression of receptorinteracting protein 3 (RIP3). Authors also showed high levels of RIP3 in human Paneth cells and increased necroptosis in the terminal ileum CD individuals and suggested a role of necroptosis in the pathogenesis of this disease. They also postulated a role of caspase- 8 in the regulation of the intestinal homeostasis and in protection of intestinal epithelial cells against necroptotic cell death by TNF- $\alpha$.

Although many studies intended to explain the imbalance and inflammation processes that occur in the gastrointestinal tract, many lacking information are still observed and multidisciplinary teams will be necessary to the comprehension of these conditions.

\section{Importance of lleoscopy}

Based on the fact that the diagnostic value of ileoscopy is not well documented, Young and Heymann [23] developed a retrospective study with 2,149 patients undergoing colonoscopy. In $16.1 \%$ (346 patients), the terminal ileum was intubated and histologic abnormalities were found in 16, resulting in a diagnostic yield of $4.6 \%$ of all ileoscopies and authors concluded that this procedure should only be performed when the indication is warranted and that it could interfere in the management. They also suggested that it is not cost-effective to attempt ileum intubation in all patients.

Jeong et al [24] also worried about if the terminal ileum intubation should be used routinely in patients undergoing colonoscopy. With this worry, they investigated the possible diagnostic of terminal ileum intubation during colonoscopy. These authors studied 3,921 individuals undergoing colonoscopy and their results showed that the terminal ileum was intubated in $87.1 \%$ of the patients $(3,417$ individuals) and macroscopic abnormality on terminal ileum was found in almost $4 \%$ (125 cases). These abnormalities included ulcers, erosions or aphthous ulcers, nodular or erythematous mucosa, and polypoid lesions. In almost 92\%, they found non-specific histological observations not thought to be clinically significant, such as low-grade mucosal damage, non-specific inflammation, and lymphoid hyperplasia. None of these individuals had chronic or recurrent bowel symptoms for a month and the findings related to the TI were not of clinical importance. Histopathology relevance was found in almost 9\%. Seven cases were diagnosed as CD, three with intestinal tuberculosis (ITB), and one with Adamantiades-Behcet's disease. Authors have concluded that intubation during colonoscopy is capable to identify significant pathology in almost $2 \%$ of patients possessing right lower quadrant abdominal pain, and $0.4 \%$ in patients with diarrhea. As the diagnostic yield is very low in other indications for colonoscopy, the performance or not of ileoscopy needs to be based on case-by-case.

\section{Conditions Related to lleitis}

As pointed before, ileitis is defined as inflammation of the ileum 
Table 1. Summary of the Conditions Related to the Development of $\mathrm{TI}$ (Modified From [3, 4])

\begin{tabular}{|c|c|}
\hline Classification & Condition \\
\hline Inflammatory disease & $\begin{array}{l}\text { Crohn's disease } \\
\text { Ulcerative colitis (backwash ileitis) }\end{array}$ \\
\hline Anatomic alteration & Meckel's diverticulum \\
\hline Drug intake & $\begin{array}{l}\text { Non-steroidal anti-inflammatory } \\
\text { Antihypertensives } \\
\text { Digoxin } \\
\text { Diuretics } \\
\text { Ergotamine } \\
\text { Oral contraceptives }\end{array}$ \\
\hline Vascular conditions & $\begin{array}{l}\text { Ischemia } \\
\text { Behcet's disease } \\
\text { Giant-cell arteritis } \\
\text { Henoch-Schonlein purpura } \\
\text { Lymphomatoid granulomatosis } \\
\text { Polyarteritis nodosa } \\
\text { Systemic lupus erythematosus } \\
\text { Wegener granulomatosis }\end{array}$ \\
\hline Intestinal infection & $\begin{array}{l}\text { Actinomycosis } \\
\text { Anisakiasis } \\
\text { Clostridium difficile } \\
\text { Cryptococcus neoformans } \\
\text { Cytomegalovirus } \\
\text { Mycobacterium tuberculosis } \\
\text { Neutropenic enterocolitis } \\
\text { Salmonella spp. } \\
\text { Yersinia enterocolitica and } \\
\text { Y. pseudotuberculosis }\end{array}$ \\
\hline Spondyloarthropathies & $\begin{array}{l}\text { Ankylosing spondylitis } \\
\text { Arthritis associated with } \\
\text { inflammatory bowel disease } \\
\text { Psoriasis with arthritis } \\
\text { Reactive arthritis } \\
\text { Undifferentiated spondylarthropathy }\end{array}$ \\
\hline Malignant diseases & $\begin{array}{l}\text { Carcinoid tumor } \\
\text { Cecal adenocarcinoma } \\
\text { Ileal adenocarcinoma } \\
\text { Lymphoma } \\
\text { Lymphosarcoma } \\
\text { Metastatic cancer }\end{array}$ \\
\hline Infiltrative & $\begin{array}{l}\text { Amyloidosis } \\
\text { Eosinophilic enteritis } \\
\text { Sarcoidosis }\end{array}$ \\
\hline
\end{tabular}

and is commonly related to CD. Nevertheless, many diseases can be related to this condition, such as ulcerative colitis (UC), the intake of non-steroidal anti-inflammatory drugs (NSAID), infectious diseases, eosinophilic enteritis, lymphoma, lymphoid hyperplasia, radiation enteritis, spondyloarthropathies, vasculitides, ischemia, neoplasms, sarcoidosis, amyloidosis, and others. These conditions may affect the ileum and could mimic CD, both histologically and endoscopically [4].

Table 1 summarizes some conditions related to TI. As we pointed before the correct diagnosis of the cause of the ileitis is indispensable for a good therapeutic approach of the patient. Some of the main conditions related to ileitis are described below.

\section{Inflammatory bowel disease (IBD)}

$\mathrm{CD}$ and UC are polygenic autoimmune diseases with multifactorial etiology sharing similar peculiarities as risk factors, clinical, endoscopic and histological patterns, and genetic predisposition. The manifestations are systemic and may lead to a serious damage to the gastrointestinal tract, and extra-intestinal manifestations. On the other hand, in UC inflammation pattern is normally restricted to the mucosal surface, starting in the rectum and extending in a uniform pattern throughout the colon and rarely affecting the terminal ileum [25].

\section{$C D$}

The inflammation of the ileum is often caused by CD that manifests due to an idiopathic transmural inflammation affecting all the wall layers and may occur from mouth to anus but the most common affected site is the distal ileum. Skipped areas of inflammation can be found and this process leads to formation of ulcers that may produce penetrating (fistulizing), fibrostenotic (stricturing), or inflammatory pattern in the perianal region and abdominal wall [26-28].

This disorder was described by Crohn in 1932 after studying 14 cases of TI. CD patterns involve transmural inflammation, thickened submucosa, fissuring ulceration and non-caseating granulomas. It is frequently followed by a number of symptoms such as abdominal pain, diarrhea, gastrointestinal bleeding, malabsorption, and weight loss, and may lead to lifethreatening complications [29, 30].

The primary location of CD, in approximately two-thirds of cases, is the small intestine, specifically the terminal ileum, probably due to disruption in the immune response to environmental factors in genetically predisposed individuals and the commonly presence of erosions and ulcers is referred normally to $\mathrm{CD}$. Results of CD biopsies show an inflammatory cellular infiltrate with crypt abscesses, architectural distortion, and occasional granulomas. Nevertheless, the exclusion of other possibilities of TI requires the performance of a clinic, laboratory, endoscopic, and histopathological evaluation of the individuals $[3,31-33]$.

\section{UC: backwash ileitis (BWI)}

When TI is observed in UC, the name used is BWI that refers to an inflammation process in the distal few centimeters of terminal ileum. This inflammation condition of the ileum occurs due to reduced ileocecal valve function in severe UC (when present, may indicate the differential diagnosis of CD), allowing for retrograde flow of colonic content and inflammation of the ileum. There is stasis that occurs from inflammation-induced colonic hypomotility, or continuous extension of inflammation 
from the colon. This ileitis is normally mild and is related to neutrophilic inflammation in the lamina propria, focal cryptitis/ crypt abscesses and, rarely, superficial mucosal erosions. Occasionally it may only exhibit mucosal injury, as villous blunting and regenerative epithelial changes. It can be differentiated from $C D$ by the large length of involved small bowel separated by skip regions in the cecum or distal ileum, higher inflammatory process and mucosal injury in the ileum, transmural ileal inflammation and neural hyperplasia, and mucous gland metaplasia of the ileal mucosa. Literature also reports that ileal changes in UC may reach $17 \%$. Normally, the severity of ileum inflammation parallels the severity of the colonic activity, commonly with pancolitis and cecal involvement [3, 34-36].

UC "Crohn-like", coming from a chronic pancreatic enzyme taking, has been also described in the literature $[26,37$, 38].

A conclusive diagnostic criterion for BWI is not available, but we should consider an active enteritis affecting the ileum in a contiguous pattern from cecum with a similar or higher degree of inflammation. The differentiation of Crohn's ileocolitis and "panulcerative" colitis with BWI is direct when granulomas are found on "histology or aphthous ulcers, cobblestoning, and skip lesions are seen endoscopically, but can be a clinical challenge when these features are absent" [4].

\section{Ileitis and IBD associated with primary sclerosing cholangi- tis (PSC)}

Background PSC is normally associated with UC and ileocolitis in CD. IBD in PSC is considered to be a quiescent disease, and pancolitis occurs often (but not necessarily), with rates varying from $35 \%$ to $95 \%$. Both BWI and rectal sparing are observed infrequently. The reported rates of BWI found for PSC-UC vary from $5.0 \%$ to $42.9 \%$. In UC without PSC, the involvement of the ileum is not frequent, ranging from $2.5 \%$ to $24 \%$ [34, 39-41].

\section{Meckel's diverticulum}

Meckel's diverticulum (MD) represents the most common congenital anomalies of the digestive tract that occurs in the gastrointestinal tract, reaching an incidence of $2-4 \%$ in the general population, although most patients are asymptomatic. This anomaly refers to the persistence of the embryological connection between the umbilical and bowel. Symptomatic cases usually course with hemorrhage, intestinal obstruction, ulceration, perforation, inflammation, intussusceptions, and malignant transformation [42-45].

Many studies have shown the association among MD and $\mathrm{CD}$, and some authors postulate that ileitis is attributable to acid-secreting gastric heterotopia. Complications of MD are more frequent in male and younger individuals. Bleeding occurs more frequently in adult males and in children, mainly younger than 4 years of age, and it occurs mainly as obstruction [43-45].

In a recent study with 48 adult individuals, Hamilton and Arnason [46] found that some of them presented inflammatory modifications in the small intestine neighboring the diverticu- lum and concluded that the ileitis reaching short segment of mucosa and submucosa near MD is common, and is not necessarily associated to $\mathrm{CD}$.

\section{Use of NSAIDs}

Aspirin and NSAIDs are related to the reduction of colorectal adenoma and cancer risk but on the other hand, it is also related to injury of the gastrointestinal mucosal. These drugs are mainly involved in the inhibition of cyclooxygenase or prostaglandin-endoperoxide synthase enzymes. The interference that they promote in the intestinal epithelial barrier occurs possibly in the interaction between the gut microbiota and immune cells, thus increasing risk for IBD. Another view of the effects of aspirin and NSAIDs is the effects on the liberation of inflammatory markers and platelet aggregation which may induce the occurrence of IBD pathogenesis $[47,48]$.

Ashwin et al [49] performed a study with a large number of patients for 20 years and concluded that women who used NSAIDs but not aspirin showed increased risk for IBD in middle age. Authors say that although aspirin and NSAIDs share potential for gastrointestinal toxicity, aspirin was not much associated with IBD in their study probably because of the differences among the action mechanism of aspirin and NSAIDs on the COX isoenzymes. The first class of drugs at analgesic doses inhibits both the COX-1 and COX-2 enzymes while aspirin at low and moderate doses is COX-1-selective. In animal models of colitis, authors showed that inhibition of COX-1 or COX-2 alone does not lead to colitis, but the use of non-selective NSAIDs which are inhibitors of both isoenzymes results in early development of colitis. The deleterious actions of aspirin may also have a counterbalance by the anti-inflammatory or mucosal protective effects. In mice, authors have shown that inhibitors of sphingosine kinase may exhibit therapeutic against colitis $[50,51]$.

In view of the above, doctors should take into account the use of these medications as being part of the managing protocol of ileitis.

\section{Behcet's disease (BD)}

$\mathrm{BD}$ is a multi-systemic inflammatory condition with unknown etiology and presence of a chronic recurrent clinical course characterized by repeated oral and genital ulcerations, arthritis, vasculitis, ocular lesions, skin manifestations, and gastrointestinal involvement. Intestinal BD may affect 3-60\% of patients suffering with BD. The incidence of intestinal BD is more frequent in East Asian countries than in Western or Middle Eastern countries. Any part of the gastrointestinal tract may be affected but the most common location is the ileocecal area. The main endoscopic aspects found are few, large, and deep ulcerations with discrete border. The intestinal BD has many similarities with IBD regarding clinical manifestations, genetics, and therapeutic strategies (biologic agents such as anti-TNF- $\alpha$ antibody), what makes the differentiation of both conditions clinically not easy. Doctors need to require com- 
prehensive knowledge regarding the similar characteristics of both diseases in order to make an accurate clinical decision $[1,52]$. The main differences compared to $C D$ are the large size of ulcerations on the ileocecal area (round or oval shaped and more discrete and elevated border), fewer number of lesions, non-specific inflammation (lymphocytic or neutrophilic infiltrations), presence of vasculitis (possible) and absence of non-caseating granuloma [1].

On the other side, innumerous ulcerations from small aphthous ulcerations to multiple irregular shaped ulcerations may appear. Lee et al [53] compared colonoscopy findings of 115 intestinal $\mathrm{BD}$ and $135 \mathrm{CD}$ individuals and found that round shape, fewer number, focal distribution, and absence of aphthous and cobblestone appearance were independent discriminating factors of intestinal BD. Colonoscopy findings for $\mathrm{BD}$ relate five or fewer lesions, oval shape, deep penetrating, discrete border, and ileocecal location as typical ulcerations. Other classification for macroscopic aspects of intestinal BD ulcerations is volcano, geographic, and aphthous types. In $\mathrm{CD}$, the classical aspects found in the colonoscopy may show aphthous ulcerations, discontinuous chronic mucosal inflammation, longitudinal ulcerations, and cobblestone appearance with normal surrounding mucosa. Skipped inflammatory/normal pattern lesions are often found in $C D$, similar to those of intestinal BD but the distribution of the lesions in $\mathrm{CD}$ patients is more diffuse than in intestinal BD patients [1, 54-56].

\section{Intestinal infections}

Intestinal infections may lead to mistakes in diagnosis, and management of symptoms once they can mimic endoscopic and clinical findings of IBD. Some important intestinal infections are described below.

\section{ITB: Mycobacterium tuberculosis}

Extra-pulmonary tuberculosis is becoming common due to HIV infection and treatment and the development is more related $(70 \%$ of the cases) after ingesting infected sputum in cases of active pulmonary tuberculosis. The gastrointestinal tract involvement produces a similar pattern of CD and the distinction of both is related to clinical and histological evaluations if culture is negative. The most affected areas are ileocecal and jejuno-ileum probably resulting from high densities of lymphoid aggregates, neutral $\mathrm{pH}$ environment allowing swallowed mycobacterium to be absorbed and physiologic stasis. Authors have shown that the ileocecal area has been involved in about $90 \%$ of ITB patients $[4,57]$. Both conditions lead to abdominal pain and mass in the right lower quadrant, presence of ulcerations, and fibrotic lesions resulting in bowel obstructions and fistulae formations. Besides, both conditions may coexist. Due to chronic inflammation, the ileal wall may become fibrotic or stenotic or may form tuberculomas leading to intestinal obstruction or perforation. The differentiation may be based on the presence of anorectal lesions, longitudinal ulcers, aphthous ulcers, and a cobblestone pattern what would indicate CD or the observation of a patulous ileocecal valve, transverse ulcers, and pseudo-polyps would indicate intestinal tuberculosis. ITB patients may present fever, abdominal pain, a palpable mass, modification of the bowel habits, and/or bleeding. The comparison of clinical and endoscopic aspects, culture and polymerase chain reaction for Mycobacterium tuberculosis (positive TB culture is the gold standard diagnosis although it may delay weeks), biopsy, and radiology should drive doctor to a conclusion $[3,53,58,59]$.

\section{Yersinia enterocolitica and Yersinia pseudotuberculosis}

These microorganisms are mainly acquired more commonly by ingestion of contaminated water or food and the most frequent clinical aspect is the presence of enterocolitis with pain, diarrhea, low-grade fever, mucosal ulceration, neutrophil invasion, thickening of the ileal wall (leading to perforation), rectal bleeding, reactive polyarthritis and septicemia. Diagnosis is by stool culture and colonoscopy with biopsy. Endoscopic patterns include aphthoid lesions of the cecum and TI with round or oval elevations with ulcerations that are mostly uniform in size and shape, in contrast to CD. The formation of fistula and fibrotic stenosis appears commonly in CD [4, 60-62].

\section{Salmonella}

Salmonella enteritidis (non-typhoidal Salmonella) infection may occur in the foodborne leading to the passage of pathogens to the gut epithelial cell and with secondary translocation to the extra-intestinal organs as spleen and liver and the infection is a very common cause of foodborne illness that occurs with the ingestion of contaminated food products. Typhoid fever occurs due to the presence of Salmonella enterica serotype Typhi and it is transmitted person to person [63, 64].

Authors have found that hematochezia secondary to typhoid colitis affects mainly terminal ileum followed by the ileocecal valve, ascending and transverse colon. Besides, infection caused by Salmonella decreases the antioxidant capacity in the ileal loops due to the reduction of enterocyte glutathione levels. This condition raises the susceptibility of epithelial cells to oxidative damage $[63,64]$.

The infections promoted by Salmonella most often cause self-limited acute gastroenteritis, bacteremia, and vascular infections. The TI leads to circumferential and homogenous thickening of the terminal ileum wall but its differentiation from other causes of ileitis, as in CD, is not easy. Endoscopy procedures with biopsy may help but the definite diagnosis of Salmonella is based on culture [4, 65].

\section{Clostridium difficile}

A disrupted microbiota with loss of colonization resistance is the main cause of Clostridium difficile infection and it normally causes antibiotic-associated colitis. Enteritis related to Clostridium difficile toxin is a nosocomial disease of increas- 
ing clinical concern, but inflammation process is unknown. The symptoms normally are related to abdominal or pelvic pain, low-grade fevers, and increased ileostomy output. The diagnosis may be performed by observing pseudomembranes and stool studies showing toxin-producing organisms [66-68].

\section{Malignant diseases}

Small bowel cancer is a relatively rare malignant disease that occurs in only $2 \%$ of all gastrointestinal cancers. However, the incidence is increasing, mainly in North America and Europe. Authors' estimate of 5,300 patients, in the United States, and 3,500 in Europe and approximately one-third of cases are related to prior or subsequent other gastrointestinal tract tumors. The most common malignancy lesions are adenocarcinoma, gastrointestinal stromal tumors (GIST), carcinoids or lymphomas. Malignant involvement of the ileum, in almost half of the cases, refers to lymphoma [69-71].

Still in a symptomatic phase more than $50 \%$ of patients present metastasis. Due to this malignancy and knowing the specificity of the clinical picture, the professional should perform a deep approach of the disease in order to reach an early diagnosis and consequently possibility of successful in the treatment [71].

The carcinogenesis pathway seems to be associated to the host-bacteria interaction, with changes in the intestinal stem cell function. The chronic inflammation process and secondary and hyper proliferation of the intestinal stem cells initiate malignant modifications, maintenance and metastases. Carcinoids and lymphomas affect mainly the ileum in a proportion of $87 \%$ and $60 \%$, respectively. A study from Canada showed that adenocarcinomas occur in the ileum in 16\% [72-74].

The small bowel adenocarcinoma presents non-specific clinical manifestation and most lesions occur within $25 \mathrm{~cm}$ of the duodeno-jejunal junction. For this reason, individuals presenting pain, vomiting, and anemia should have proximal jejunum as part of the investigation. Most duodenal carcinomas are polypoid and the larger lesions may form ulcerations. The appearance of the mesenteric small bowel carcinomas includes mucosal destruction, irregular luminal narrowing, and rigidity of a short segment, and areas of intestinal obstruction. The distinction from $\mathrm{CD}$ is that this pathology normally reaches longer segments, and an appearance of cobblestone is observed. Lymphoma and leiomyosarcoma normally are seen as larger and softer tumors $[3,75,76]$.

The small bowel lymphoma originates in the lymphoid follicle of the submucosa and may encircle the bowel, leading to narrowing of the lumen and mimic CD in different ways such as clinically, radiologically and endoscopically. It is possible to find single or multiple segmental thickened areas, circumferential thickening, or ulcerations and consequent development of a fistulous tract to adjacent bowel loops, similar to CD $[70,77]$.

\section{Eosinophilic gastroenteritis (EG)}

Eosinophilic gastrointestinal disorders may occur in adults and consist in two types known as EG, that occur due to pathological eosinophile infiltration (without known causes of eosinophilia such as parasitic infection, malignancy, and drug reaction) in the gastrointestinal wall independently of esophageal involvement and eosinophilic esophagitis, characterized by dense infiltration of eosinophile only in esophageal mucosa. EG is considered a non-IgE-dependent T helper 2 type allergic and possibly the food allergens are responsible to the triggering and aggravating factors as the modifications in the mucosal integrity, culmination in the presence of several antigens in the gut wall, resulting in tissue and blood eosinophilia. The main symptoms are abdominal pain and diarrhea $[4,78]$.

EG may reach the stomach and small intestine, and sometimes the colon. Patients with small-bowel EG may have abdominal pain, diarrhea, or malabsorption and ileal strictures and bowel obstruction may be observed with muscle layer involvement. Endoscopic procedures are limited to identify the presence of EG once the typical endoscopic alterations are not specific (erosion, erythema, nodularity, and edema). On the other hand, a multiple biopsy-based histopathological diagnosis is crucial. Diffuse enteritis with complete loss of villi, submucosal edema, and fibrosis may be present. In EG, there is no typical architectural distortion found in individuals with CD what could help in the differentiation of these two pathologies. Furthermore, the presence of peripheral eosinophilia and/ or an eosinophil-rich tissue infiltrate is rare in $\mathrm{CD}$ patients $[4$, 79-81].

\section{Conclusion}

The inflammation of the ileum may occur due to different pathological conditions leading to difficulties in the diagnosis. Normally it is associated to CD but it may also occur, in UC, $\mathrm{BD}$, malignant pathologies, infectious diseases, EG and use of NSAIDs. Although TI occurs in higher percentage in CD, an individual approach is necessary to differentiate from the other conditions once the correct diagnosis is crucial for the immediate therapeutic approach and recovering of the patient.

\section{Conflict of Interests}

Authors declare no conflict of interests.

\section{References}

1. Kim DH, Cheon JH. Intestinal Behcet's Disease: A True Inflammatory Bowel Disease or Merely an Intestinal Complication of Systemic Vasculitis? Yonsei Med J. 2016;57(1):22-32.

2. Adamek HE, Schantzen W, Rinas U, Goyen M, Ajaj W, Esser C. Ultra-high-field magnetic resonance enterography in the diagnosis of ileitis (Neo-)terminalis: a prospective study. J Clin Gastroenterol. 2012;46(4):311-316.

3. Bojic D, Markovic S. Terminal ileitis is not always Crohn's disease. Ann Gastroenterol. 2011;24(4):271-275. 
4. Dilauro S, Crum-Cianflone NF. Ileitis: when it is not Crohn's disease. Curr Gastroenterol Rep. 2010;12(4):249258.

5. Epitome of Current Medical Literature. $\mathrm{Br}$ Med J. 1936;2(3962):E97-E100.

6. Epitome of Current Medical Literature. $\mathrm{Br}$ Med J. 1937;1(3969):E17-E20.

7. Crohn BB. The Pathology of Acute Regional Ileitis. Am J Dig Dis. 1965;10:565-572.

8. Kewenter J, Hulten L, Kock NG. The relationship and epidemiology of acute terminal ileitis and Crohn's disease. Gut. 1974;15(10):801-804.

9. Kedia S, Kurrey L, Pratap Mouli V, Dhingra R, Srivastava S, Pradhan R, Sharma R, et al. Frequency, natural course and clinical significance of symptomatic terminal ileitis. J Dig Dis. 2016;17(1):36-43.

10. de Moreno de LeBlanc A, Del Carmen S, Chatel JM, Miyoshi A, Azevedo V, Langella P, Bermudez-Humaran LG, et al. Current Review of Genetically Modified Lactic Acid Bacteria for the Prevention and Treatment of Colitis Using Murine Models. Gastroenterol Res Pract. 2015;2015:146972.

11. Tomasello G, Tralongo P, Amoroso F, Damiani P, Sinagra E, Noto M, Arculeo VM, et al. Dysmicrobism, Inflammatory Bowel Disease and Thyroiditis: Analysis of the Literature. J Biol Regul Homeost Agents. 2015;29(2):265272.

12. Nee J, Feuerstein JD. Optimizing the Care and Health of Women with Inflammatory Bowel Disease. Gastroenterol Res Pract. 2015;2015:435820.

13. Souza MSS, Barbalho SM, Goulart RA, Carvalho ACA. Inflammatory bowel disease: how can traditional therapy help? Pharmacology online. 2015:2:1-9.

14. Eder P, Lykowska-Szuber L, Krela-Kazmierczak I, Stawczyk-Eder K, Iwanik K, Majewski P, Sterzynska K, et al. Disturbances in apoptosis of lamina propria lymphocytes in Crohn's disease. Arch Med Sci. 2015;11(6):1279-1285.

15. Tabbaa M, Golubic M, Roizen MF, Bernstein AM. Docosahexaenoic acid, inflammation, and bacterial dysbiosis in relation to periodontal disease, inflammatory bowel disease, and the metabolic syndrome. Nutrients. 2013;5(8):3299-3310.

16. Lucas K, Morris G, Anderson G, Maes M. The Toll-Like Receptor Radical Cycle Pathway: A New Drug Target in Immune-Related Chronic Fatigue. CNS Neurol Disord Drug Targets. 2015;14(7):838-854.

17. Serhan CN, Savill J. Resolution of inflammation: the beginning programs the end. Nat Immunol. 2005;6(12):11911197.

18. Elia PP, Tolentino YF, Bernardazzi C, de Souza HS. The role of innate immunity receptors in the pathogenesis of inflammatory bowel disease. Mediators Inflamm. 2015;2015:936193.

19. Gomez-Llorente C, Munoz S, Gil A. Role of Toll-like receptors in the development of immunotolerance mediated by probiotics. Proc Nutr Soc. 2010;69(3):381-389.

20. Artom M, Czuber-Dochan W, Sturt J, Norton C. Targets for Health Interventions for Inflammatory Bowel Disease-fatigue. J Crohns Colitis. 2016.
21. Larsen MD, Qvist N, Nielsen J, Kjeldsen J, Nielsen RG, Norgard BM. Use of Anti-TNFalpha Agents and Time to First-time Surgery in Paediatric Patients with Ulcerative Colitis and Crohn's Disease. J Crohns Colitis. 2016.

22. Gunther C, Martini E, Wittkopf N, Amann K, Weigmann B, Neumann H, Waldner MJ, et al. Caspase- 8 regulates TNF-alpha-induced epithelial necroptosis and terminal ileitis. Nature. 2011;477(7364):335-339.

23. Yoong KK, Heymann T. It is not worthwhile to perform ileoscopy on all patients. Surg Endosc. 2006;20(5):809811.

24. Jeong SH, Lee KJ, Kim YB, Kwon HC, Sin SJ, Chung JY. Diagnostic value of terminal ileum intubation during colonoscopy. J Gastroenterol Hepatol. 2008;23(1):51-55.

25. Goulart RA, Barbalho SM, Gasparini RG, Carvalho ACA. Inflammatory Bowel Disease: General Aspects and Role of Inflammatory Markers. Int J Inflamm Bowel Dis. 2015;1(2):62-68.

26. Birindelli A, Tugnoli G, Beghelli D, Siciliani A, Biscardi A, Bertarelli C, Selleri S, et al. Emergency laparoscopic ileo-colic resection and primary intracorporeal anastomosis for Crohn's acute ileitis with free perforation and faecal peritonitis: first ever reported laparoscopic treatment. Springerplus. 2016;5:16.

27. Fessatou S, Georgantzi GG, Shtukkert E, Matsota P, Loumou P, Polymeros D, Triantafyllou K. Chronic lip swelling as the sole presentation of Crohn's disease: three case reports. Turk J Pediatr. 2015;57(1):98-101.

28. Mosli M, Al Beshir M, Al-Judaibi B, Al-Ameel T, Saleem A, Bessissow T, Ghosh S, et al. Advances in the diagnosis and management of inflammatory bowel disease: challenges and uncertainties. Saudi J Gastroenterol. 2014;20(2):81-101.

29. Panes J, Gomollon F, Taxonera C, Hinojosa J, Clofent J, Nos P. Crohn's disease: a review of current treatment with a focus on biologics. Drugs. 2007;67(17):2511-2537.

30. Beck AT, Ward CH, Mendelson M, Mock J, Erbaugh J. An inventory for measuring depression. Arch Gen Psychiatry. 1961;4:561-571.

31. Peyrin-Biroulet L, Loftus EV, Jr., Colombel JF, Sandborn WJ. The natural history of adult Crohn's disease in population-based cohorts. Am J Gastroenterol. 2010;105(2):289-297.

32. Pizarro TT, Pastorelli L, Bamias G, Garg RR, Reuter BK, Mercado JR, Chieppa M, et al. SAMP1/YitFc mouse strain: a spontaneous model of Crohn's disease-like ileitis. Inflamm Bowel Dis. 2011;17(12):2566-2584.

33. Smith JP, Bingaman SI, Ruggiero F, Mauger DT, Mukherjee A, McGovern CO, Zagon IS. Therapy with the opioid antagonist naltrexone promotes mucosal healing in active Crohn's disease: a randomized placebo-controlled trial. Dig Dis Sci. 2011;56(7):2088-2097.

34. de Vries AB, Janse M, Blokzijl H, Weersma RK. Distinctive inflammatory bowel disease phenotype in primary sclerosing cholangitis. World J Gastroenterol. 2015;21(6):1956-1971.

35. DeRoche TC, Xiao SY, Liu X. Histological evaluation in ulcerative colitis. Gastroenterol Rep (Oxf). 2014;2(3):178-192. 
36. Haskell H, Andrews CW, Jr., Reddy SI, Dendrinos K, Farraye FA, Stucchi AF, Becker JM, et al. Pathologic features and clinical significance of "backwash" ileitis in ulcerative colitis. Am J Surg Pathol. 2005;29(11):14721481.

37. Croft NM, Marshall TG, Ferguson A. Gut inflammation in children with cystic fibrosis on high-dose enzyme supplements. Lancet. 1995;346(8985):1265-1267.

38. FitzSimmons SC, Burkhart GA, Borowitz D, Grand RJ, Hammerstrom T, Durie PR, Lloyd-Still JD, et al. Highdose pancreatic-enzyme supplements and fibrosing colonopathy in children with cystic fibrosis. N Engl J Med. 1997;336(18):1283-1289.

39. Moussata D, Boschetti G, Stefanescu C, Nancey S, Bouhnik Y, Flourie B. Isolated ileitis associated with primary sclerosing cholangitis in three patients with Crohn's disease. Scand J Gastroenterol. 2016;51(6):727-730.

40. Paine ER. Colonoscopic evaluation in ulcerative colitis. Gastroenterol Rep (Oxf). 2014;2(3):161-168.

41. Boonstra K, van Erpecum KJ, van Nieuwkerk KM, Drenth JP, Poen AC, Witteman BJ, Tuynman HA, et al. Primary sclerosing cholangitis is associated with a distinct phenotype of inflammatory bowel disease. Inflamm Bowel Dis. 2012;18(12):2270-2276.

42. Tummers WS, van der Vorst JR, Swank DJ. Traumatic rupture of a Meckel's diverticulum due to blunt abdominal trauma in a soccer game: A case report. Int J Surg Case Rep. 2016;19:8-10.

43. Itriyeva K, Harris M, Rocker J, Gochman R. Not Just Painless Bleeding: Meckel's Diverticulum as a Cause of Small Bowel Obstruction in Children-Two Cases and a Review of the Literature. Case Rep Emerg Med. 2015;2015:938346.

44. Pandiaraja J. Spontaneous Rupture of Adenocarcinoma of Meckel's Diverticulum- A Rare Entity. J Clin Diagn Res. 2015;9(11):PD13-14.

45. Turgeon DK, Barnett JL. Meckel's diverticulum. Am J Gastroenterol. 1990;85(7):777-781.

46. Hamilton CM, Arnason T. Ileitis associated with Meckel's diverticulum. Histopathology. 2015;67(6):783-791.

47. Huang ES, Strate LL, Ho WW, Lee SS, Chan AT. Longterm use of aspirin and the risk of gastrointestinal bleeding. Am J Med. 2011;124(5):426-433.

48. Musumba C, Pritchard DM, Pirmohamed M. Review article: cellular and molecular mechanisms of NSAID-induced peptic ulcers. Aliment Pharmacol Ther. 2009;30(6):517-531.

49. Ashwin NA, Higuchi LM, Huang ES, Khalili H, Richter JM, Fuchs CS, Chan AT. Aspirin, Nonsteroidal Antiinflammatory Drug Use, and Risk for Crohn Disease Ulcerative Colitis. A Cohort Study Ann Intern Med. 2012;156(5):350-359.

50. Maines LW, Fitzpatrick LR, French KJ, Zhuang Y, Xia Z, Keller SN, Upson JJ, et al. Suppression of ulcerative colitis in mice by orally available inhibitors of sphingosine kinase. Dig Dis Sci. 2008;53(4):997-1012.

51. Chumanevich AA, Poudyal D, Cui X, Davis T, Wood PA, Smith CD, Hofseth LJ. Suppression of colitis-driven colon cancer in mice by a novel small molecule inhibitor of sphingosine kinase. Carcinogenesis. 2010;31(10):17871793.

52. James DG. Behcet's syndrome. $\mathrm{N}$ Engl $\mathrm{J}$ Med. 1979;301(8):431-432.

53. Lee YJ, Yang SK, Byeon JS, Myung SJ, Chang HS, Hong $\mathrm{SS}$, Kim KJ, et al. Analysis of colonoscopic findings in the differential diagnosis between intestinal tuberculosis and Crohn's disease. Endoscopy. 2006;38(6):592-597.

54. Kim DH, Chan HC, Lung PFC, Ng SC, Cheon JH. Ileocolonoscopy in Crohn's disease. In: Kim WH, Cheon $\mathrm{JH}$, editors. Atlas of inflammatory bowel diseases. 1st ed. New York: Springer Berlin Heidelberg; 2015. p.31-51.

55. Cheon JH, Kim ES, Shin SJ, Kim TI, Lee KM, Kim SW, Kim JS, et al. Development and validation of novel diagnostic criteria for intestinal Behcet's disease in Korean patients with ileocolonic ulcers. Am J Gastroenterol. 2009;104(10):2492-2499.

56. Lee SK, Kim BK, Kim TI, Kim WH. Differential diagnosis of intestinal Behcet's disease and Crohn's disease by colonoscopic findings. Endoscopy. 2009;41(1):9-16.

57. Zhang T, Fan R, Wang Z, Hu S, Zhang M, Lin Y, Tang $\mathrm{Y}$, et al. Differential diagnosis between Crohn's disease and intestinal tuberculosis using integrated parameters including clinical manifestations, T-SPOT, endoscopy and CT enterography. Int J Clin Exp Med. 2015;8(10):1757817589.

58. Masood I, Majid Z, Rafiq A, Rind W, Zia A, Raza S. Multiple, Pan-Enteric Perforation Secondary to Intestinal Tuberculosis. Case Rep Surg. 2015;2015:318678.

59. Leung VK, Law ST, Lam CW, Luk IS, Chau TN, Loke $\mathrm{TK}$, Chan WH, et al. Intestinal tuberculosis in a regional hospital in Hong Kong: a 10-year experience. Hong Kong Med J. 2006;12(4):264-271.

60. Laji N, Bowyer R, Jeyaratnam D, Zuckerman M. Another mistaken case of appendicitis. BMJ Case Rep. 2015;2015.

61. Laporte J, Savin C, Lamourette P, Devilliers K, Volland $\mathrm{H}$, Carniel E, Creminon C, et al. Fast and sensitive detection of enteropathogenic Yersinia by immunoassays. J Clin Microbiol. 2015;53(1):146-159.

62. Navarro-Llavat M, Domenech E, Masnou H, Ojanguren I, Manosa M, Lorenzo-Zuniga V, Boix J, et al. Collagenous duodeno-ileo-colitis with transient IgG deficiency preceded by Yersinia enterocolitica intestinal infection: case report and review of literature. Gastroenterol Hepatol. 2007;30(4):219-221.

63. De Mel S, Wong RK. Massive gastrointestinal hemorrhage secondary to typhoid colitis: A case report and literature review. IDCases. 2015;2(3):83-85.

64. van Ampting MT, Schonewille AJ, Vink C, Brummer RJ, van der Meer R, Bovee-Oudenhoven IM. Intestinal barrier function in response to abundant or depleted mucosal glutathione in Salmonella-infected rats. BMC Physiol. 2009;9:6.

65. Balthazar EJ, Charles HW, Megibow AJ. Salmonella- and Shigella-induced ileitis: CT findings in four patients. J Comput Assist Tomogr. 1996;20(3):375-378.

66. Bhargava A, Clifton MS, Mhaske P, Liao M, Pothoulakis C, Leeman SE, Grady EF. Local injection of dsRNA targeting calcitonin receptor-like receptor (CLR) amelio- 
rates Clostridium difficile toxin A-induced ileitis. Proc Natl Acad Sci U S A. 2013;110(2):731-736.

67. Seril DN, Ashburn JH, Lian L, Shen B. Risk factors and management of refractory or recurrent clostridium difficile infection in ileal pouch patients. Inflamm Bowel Dis. 2014;20(12):2226-2233.

68. Butler D, Torres-Torres S, Pahud B, Myers A, St Peter $\mathrm{SD}, \mathrm{McCulloh}$ R. Clostridium Difficile Ileitis in Pediatric Inflammatory Bowel Disease: a Case Report and Literature Review. J Pediatr Gastroenterol Nutr. 2015.

69. Islam RS, Leighton JA, Pasha SF. Evaluation and management of small-bowel tumors in the era of deep enteroscopy. Gastrointest Endosc. 2014;79(5):732-740.

70. Tangkittikasem N, Boonyaarunnate T, Aswakul P, Kachintorn U, Prachayakul V. Clinical, Radiologic, and Endoscopic Manifestations of Small Bowel Malignancies: a First Report from Thailand. Asian Pac J Cancer Prev. 2015;16(18):8613-8618.

71. Negoi I, Paun S, Hostiuc S, Stoica B, Tanase I, Negoi RI, Beuran M. Most small bowel cancers are revealed by a complication. Einstein (Sao Paulo). 2015;13(4):500-505.

72. Liu KS, Wong IO, Leung WK. Helicobacter pylori associated gastric intestinal metaplasia: Treatment and surveillance. World J Gastroenterol. 2016;22(3):1311-1320.

73. Sun J. Enteric bacteria and cancer stem cells. Cancers (Basel). 2010;3(1):285-297.

74. Gabos S, Berkel J, Band P, Robson D, Whittaker H. Small bowel cancer in western Canada. Int J Epidemiol. 1993;22(2):198-206.

75. Ye Z, Lin Y, Cao Q, He Y, Xue L. Granulomas as the Most Useful Histopathological Feature in Distinguishing between Crohn's Disease and Intestinal Tuberculosis in Endoscopic Biopsy Specimens. Medicine (Baltimore). 2015;94(49):e2157.

76. Onaka T, Kitagawa T, Mori M, Yonezawa A, Imada K. Infliximab therapy for Crohn's-like gastrointestinal lesions after allogeneic bone marrow transplantation. Rinsho Ketsueki. 2015;56(12):2452-2455.

77. Bandi M, Scagliarini L, Anania G, Pedriali M, Resta G. Focus on the diagnostic problems of primary adenocarcinoma of the third and fourth portion of the duodenum. Case report. G Chir. 2015;36(4):183-186.

78. Kinoshita Y, Ishimura N, Oshima N, Mikami H, Okimoto E, Jiao DJ, Ishihara S. Recent Progress in the Research of Eosinophilic Esophagitis and Gastroenteritis. Digestion. 2016;93(1):7-12.

79. Kinoshita Y, Furuta K, Ishimaura N, Ishihara S, Sato S, Maruyama R, Ohara S, et al. Clinical characteristics of Japanese patients with eosinophilic esophagitis and eosinophilic gastroenteritis. J Gastroenterol. 2013;48(3):333339.

80. Caldwell JM, Collins MH, Stucke EM, Putnam PE, Franciosi JP, Kushner JP, Abonia JP, et al. Histologic eosinophilic gastritis is a systemic disorder associated with blood and extragastric eosinophilia, TH2 immunity, and a unique gastric transcriptome. J Allergy Clin Immunol. 2014;134(5):1114-1124.

81. Matsushita T, Maruyama R, Ishikawa N, Harada Y, Araki A, Chen D, Tauchi-Nishi P, et al. The number and distribution of eosinophils in the adult human gastrointestinal tract: a study and comparison of racial and environmental factors. Am J Surg Pathol. 2015;39(4):521-527. 